DOI: 10.2478/romneu-2014-0005

\title{
Clinical implications of internal carotid artery tortuosity, kinking and coiling: a systematic review
}

\author{
M. Zenteno ${ }^{1}$, F. Viñuela ${ }^{2}$, L.R. Moscote-Salazar ${ }^{3}$, H. Alvis-Miranda ${ }^{4}$, \\ R. Zavaleta ${ }^{5}$, A. Flores ${ }^{6}$, A. Rojas ${ }^{7}$, A. Lee ${ }^{8}$
}

${ }^{1} \mathrm{MD}$, Professor of Neurological Endovascular Therapy, Departamento de Terapia Endovascular Neurológica, Instituto Nacional de Neurología y Neurocirugía, Universidad Nacional Autónoma de México; Stroke Unit, Hospital Ángeles del Pedregal.

${ }^{2} \mathrm{MD}$, Director, Interventional Neuroradiology, Professor, UCLA Department of Radiology, Ronald Reagan UCLA Medical Center, Los Angeles, CA. 90095,

${ }^{3} \mathrm{MD}$, Facultad de Medicina, Universidad de Cartagena, Cartagena de Indias, Colombia ${ }^{4} \mathrm{MD}$, Facultad de Medicina, Universidad de Cartagena, Cartagena de Indias, Colombia ${ }^{5} \mathrm{MD}$, Departamento de Terapia Endovascular Neurológica, Instituto Nacional de Neurología y Neurocirugía, Universidad Nacional Autónoma de México; Stroke Unit, Hospital Ángeles del Pedregal. ${ }^{6} \mathrm{MD}$, Departamento de Terapia Endovascular Neurológica, Instituto Nacional de Neurología y Neurocirugía, Universidad Nacional Autónoma de México; Stroke Unit, Hospital Ángeles del Pedregal. ${ }^{7} \mathrm{MD}$, Departamento de Terapia Endovascular Neurológica, Instituto Nacional de Neurología y Neurocirugía, Universidad Nacional Autónoma de México; Stroke Unit, Hospital Ángeles del Pedregal. ${ }^{8} \mathrm{MD}$, Department of Neurosurgery, Instituto Nacional de Ciencias Médicas y Nutrición Salvador Zubirán; Stroke Unit, Hospital Ángeles del Pedregal, Mexico City, Mexico

\begin{abstract}
Anatomical variations of the internal carotid artery are diverse. Abnormalities in their geometry and paths are commonly identified by ultrasonography and angiography. The surgical correction of symptomatic CAs is better in preventing stroke compared with best medical therapy, as well as it completely eliminates the symptoms in patients with nonhemispheric symptoms.
\end{abstract}

The ICA anomalies may be dangerous and represent a risk factor for massive bleeding. Suture ligatures can penetrate and occlude torn vessels, scalpels or biting instruments can lacerate vessels, and indirectly conducted electric cauterization can burn the soft of bony tissues.

Key words: internal carotid artery, carotid kinking, carotid coiling, anatomical variation, vascular surgery.

\section{Anatomical variations of the internal carotid arteries and its clinical implications}

\section{Search strategy and selection criteria}

We identified references for this Review from PubMed searches between January, 1960 and 2014, from the reference lists of relevant articles and through searches of the authors' 
own files. Search terms included combinations of the following key words: "internal carotid artery", "kinking", "tortuosity", "clinical implications", "complications", and "clinical trials". We reviewed titles and abstracts for content relevant to the topics covered in this Review, and basic science articles were included if the authors judged their methods to be of high quality. We excluded articles if they were not published in English.

\section{Introduction}

The anatomical variations of the internal carotid artery (ICA) are diverse. The cervical segment of ICA extends from the bifurcation of the common carotid artery until its entry into the skull base, its origin is located posterior or posterolateral to the external carotid artery (ECA), then it ascends posteromedial to this vessel with a path that can be straight, curved or angled. (1,2) According to most of the anatomy references, the cervical portion of the ICA runs a straight course to the base of the cranium without branching.

The major abnormalities in the cervical segment of the ICA occur near of its origin or at the distal portion, at level of the atlas or axis. Weibel after performing 1438 angiographies of neck vessels, found that $75 \%$ of ACI kinks were placed at $2-4 \mathrm{~cm}$ of the carotid bifurcation. (3)

ICA alterations such as coiling, kinking, and tortuosity have been matter of debate because of up to date the natural history of such anomalies is not well known, furthermore, some authors consider these conditions due to a benign angiopathy, 4 while others suppose that they are burdened with disabling, even fatal neurological complications. (5) One of the main authors in the field of ICA alterations are Weibel et al (3), they defined "tortuosity" as any ripple or elongation of the ICA in an "S" or "C" fashion, while "coiling" is the elongation or redundancy of ICA configuration with a "S" exaggerated or circular configuration, finally "Kinking" is the angle of one or more segments associated with stenosis of the vessel segment.

Considering the confusion and the broad description of terms to describe irregularities (Table I) of the course of ICA is preferable to divide these alterations only in two categories, namely: the tortuosity and kinking; thus, elongation, redundancy, and "S" configurations are grouped as tortuosity, of which the vast majority have no clinical repercussion, on the other hand, kinking is considered as the acute angulation of the vessel, a condition that is considered to be acquired.

The most comprehensive definition is that of Metz, who refers to the bend of the ICA is due to an elongation of the vessel, and defined as the abrupt angulation of the vessel axis from $90^{\circ}$ or less, and in turn classified into three grades: grade 1: bending of $90-60^{\circ}$; grade 2: 60 to $30^{\circ}$; grade 3: $<30^{\circ}$. $(7,8)$ We suggest defining the tortuosity of the ICA as any degree of abnormality in the dynamics of the vessel in relation to their normal morphology, 
DOI: 10.2478/romneu-2014-0005

which is underlying structural injury of the carotid vessel. The aim of this review is to highlight the clinical implications of the carotid artery abnormalities such as kinking and tortuosity.

\section{Epidemiology}

The occurrence of carotid abnormalities (CAs), based on the anatomical, ultrasound and angiography studies, are reported to be seen in a wide range of frequency between 10 and $43 \%$ of the population with no history of atherosclerotic disease, diabetes or hypertension. $(3,9,10)$ Pioneering studies of carotid kinking showed prevalence of $5 \%$ to $25 \%$ in patients with cerebrovascular symptoms or asymptomatic carotid stenosis incidentally diagnosed. One of the most representative series of kinkings (1000 angiograms) found a prevalence of $16 \%$ in a hospital population that is widely accepted today. $(11,12)$

Table I

\begin{tabular}{|l|l|c|}
\hline TERM & \multicolumn{1}{|c|}{ DEFINITION } & Symptoms \\
\hline \multirow{5}{*}{ Kinking } & $\begin{array}{l}\text { Any sharp bend in the } \\
\text { vessel }\end{array}$ & \\
\cline { 1 - 3 } & $\begin{array}{l}\text { Mild: angulation of } \\
\text { elongated ICA with an } \\
\text { angle } \geq 60^{\circ}\end{array}$ & - \\
\cline { 2 - 3 } & $\begin{array}{l}\text { Medium: angulation of } \\
\text { elongated ICA with angle } \\
\text { between } 30^{\circ}-60^{\circ}\end{array}$ & \pm \\
\hline & $\begin{array}{l}\text { Severe: angulation of } \\
\text { elongated ICA with angle } \\
<30^{\circ}\end{array}$ & + \\
\hline
\end{tabular}

\begin{tabular}{|l|l|l|}
\hline Tortuosity & $\begin{array}{l}\text { Any ripple or elongation } \\
\text { of the ICA in an "S" or } \\
\text { "C" fashion. } \\
\text { Subsumes the elongation, } \\
\text { redundancy, undulation, } \\
\text { and S shaped curves }\end{array}$ & - \\
\hline Coiling & $\begin{array}{l}\text { Elongation or } \\
\text { redundancy of ICA } \\
\text { configuration with a "S" } \\
\text { exaggerated or circular } \\
\text { configuration }\end{array}$ & \pm \\
\hline
\end{tabular}

Kinking occurs mostly in elderly men, and is associated with atherosclerotic pathology, while coiling is more common in younger women. (13) From a series of more than 800 cases of tortuosity and kinking of the ICA, there was a predominance in terms of sex, and some of these abnormalities were bilateral. (14)

CAs are rarely observed in children or in young adults. (15) Beigelman et al16 in a series of 885 patients, aged 1 to 90 years, showed no difference in the prevalence of kinking or coiling among age groups, favoring the embryogenic mechanism of the development of CAs.

Kink in the elderly is considered to be an acquired lesion most commonly seen in patients suffering arteriosclerosis and hypertension 9,17,18 while in children and younger patients the kinks and coils are congenital. $(15,16,19)$

Acquired form of kinking and coiling is most commonly associated with aging, hypertension and traditional risk factors for atherosclerosis, $(20-22)$ it is characterized by degenerative changes and elastic tissue destruction of the vessel wall, which causes elongation of the vessel and also a bending stress, additionally in each systole there is a momentary elongation may increase the kink. (6)

The prevalence of arterial hypertension in patients with kinking appears to be greater than those without this anomaly, Pancera et al studied 
54 Zenteno et al Implications of internal carotid artery tortuosity, kinking and coiling

590 patients with neurological symptoms by ultrasound (USG) Doppler of neck vessels, and found a prevalence of $28.4 \%$ in normotensive and $37.8 \%$ in hypertensive patients, with significant difference in both groups $(\mathrm{P}<0.01)$. (21) Currently it is known that arterial blood vessels are prone to deformation when exposed to elevated blood pressure. (13,23-26) However, a clear link between vascular risk factors and kinking and coiling is still not fully understood.

As suggested by Benes et al (17), there are 2 types of kinks in adults. First, those which may be congenital and only become clinically significant at an older age, it is more common in females, and most frequently in patients in their late fourties and early fifties; the second type which are caused by arteriosclerotic changes, are usually situated at the end of an arteriosclerotic plaque.

\section{Clinical and histopathologic features}

It is generally recognized the difficulty to establish a clear relationship between clinical signs and CAs, especially because the natural history of these abnormalities. Although the incidence of these anomalies can be up to $46 \%$, as previously mentioned, the incidence of $\mathrm{CAs}$ responsible for symptomatic cerebrovascular insufficiency is $4-16 \%$. (4) Clinical presentation of kinks in general is the same as that of the regular carotid stenosis, (17) however there are cases where the two circumstances are present at same time, being difficult to establish whether the symptomatology is caused by
ICA stenosis (more likely) or concurrent kink.

It is generally accepted, that the carotid kinking may be either the source of cerebral emboli or the vessel may be temporarily occluded by head/neck rotation thus causing symptoms of cerebral ischemia. (9,27) In both instances the resulting clinical presentation may be transient ischaemic attacks (TIA) and/or completed stroke, usually a minor one, $(9,27)$, probably due to the hemodynamic changes (i.e., the flow within the kinked vessel is not laminar but turbulent) and/or thromboembolic mechanisms including flow changes due to mechanical occlusion associated with changes in head position, microembolization and flow stasis at the kink level. $(28,29)$ In the Koskas et al (9) series of 166 adult patients, predominantly strokes and TIA were observed. In the anecdotal reports on the haemodynamic significance of congenital kinking of the ICA in children, hemiparesis, loss of vision, aphasia and seizures have been described. (30)

There are some uncertainties about the pathophysiology of cerebral ischemia caused by the kink. In the case of a kink without a plaque, positional occlusion of the vessel is blamed. (17) The hemodynamic mechanism becomes important the higher the degree of bending, the blood flow can be reduced to less than $40 \%$, with an angle of $60^{\circ}$ in the ACI and $60 \%$ at an angle of $30^{\circ}$.

Isolated CAs can lead to cerebral symptoms, without the presence of 
atherosclerotic changes. The appearance of symptoms of kinking and coiling of the ICA is associated with intracranial and extracranial occlusive disease, frequent and sudden and transitory hypotension during sleep or sudden and extreme unfavorable movements of the head and neck. $(3,20,27)$ In the majority of patients, symptomatology generally withdraws with the return of the head in neutral position.

Ischemic cerebrovascular accident occurs in about $11 \%-33 \%$ of cases with CAs. (13) It has been proven that reduction in regional cerebral flow in cases of extracranial elongation of carotid segments appears with $30-35 \mathrm{~mL}$ per min (normal range $50-60 \mathrm{~mL} / \mathrm{min} / 100 \mathrm{~g}$. brain tissue). (13) However the previously mentioned, Biegelman et al (31) using Doppler echography demonstrated that carotid kinks are not a mechanism of acute cerebral ischemia, and therefore are unlikely to be a cause of neurological events or symptoms.

Histopathologic findings in the CA segment are primarily non-inflammatory and non ateroesclerotic changes of the media and intima layers. La Barbera et al (32) demonstrated that elastic and muscular tissue is substituted by loose connective tissue, configuring a metaplasia of tunica media limited to the ICA. They hypothesized that extracranial ICA, being a segment of transition between an elastic vessel (common carotid artery) and a muscular vessel (intracranial ICA), is particularly subject to metaplastic transformation, as happens in other transition zones in human body. Because the histopathological findings are suggestive of a metaplasia, the presumption that some subjects are genetically predisposed to develop ICA metaplasia following a stimulus, probably hemodynamic forces (arterial hypertension?) that in other subjects do not cause it can be done.

The changes in tunica media are mainly marked for degeneration with fragmentation and disorganization of elastic tissue, hyperplasia, and finally areas of fibromuscular hyperplasia alternating with areas of thinning of the tunica media. $(33,34)$ Concerning the origin of the CAs it is generally believed that coiling is due to embryological causes while tortuosity and kinking are ascribed to atherosclerosis or fibromuscolar dysplasia (32).

\section{Complementary studies}

The use of ultrasound examination in the ongoing clinical practice has enabled rapid, morphological and also functional studies of CAs. (13) Del Corso et al (20) had demonstrated that more than half of the number of patients with cerebrovascular symptoms had some forms of CAs diagnosed by ultrasound technique.

Cerebral angiography has been of great value in these patients, it is the gold standard to characterize anatomically the CAs, must be obtained projections of 4 intracranial vessels, it is important to assess the kink in different projections, currently with $3 \mathrm{D}$ reconstruction angiography can be accurately measured the degree of the 
kink. Dynamic studies such as cineangiography are useful to demonstrate the hemodynamic within the kinked vessel. The delay in opacification of the intracranial vessels is indicative of a major commitment secondary to the kink.

USG Doppler technique is based on the change in frequency of an echo emitted by a moving sound source, when approaching a receiver it is observed an increase in the perceived frequency and decreasing when move away. Thus, it is possible to determine blood flow velocity based on the frequency change reflected by red blood cells moving in relation to a fixed transducer. For the assessment of ACI, is a safe, effective, non-invasive and low cost method.

For carotid disease it showed a sensitivity of 83 to $86 \%$ and a specificity of $89 \%$ to $94 \%$ for stenosis greater than $70 \%$, for the ACI kinking also exist studies that have proved its usefulness, applying the Metz classification, systolic velocities greater than $120 \mathrm{~cm} / \mathrm{seg}$ support the diagnosis of hemodynamic compromise secondary to the ICA kinking. (35)

\section{Therapeutical options}

The most important study in the field that to some extent clarified the dilemma of treat medically o surgically an entity that is not completely recognized as the cause of the symptoms, was performed by Ballota et al (36), it was conducted in symptomatic patients with elongation (coiling and kinking) of the ICA, the patients were randomized to surgical treatment group $(\mathrm{n}=92)$ or to medical treatment group $(\mathrm{n}=90)$. The purpose was to determine stroke, death at 30 days and late occlusion. The incidence of late hemispheric and retinal TIA was significantly lower in the surgical group than medical treatment group, $7,6 \%$ vs. $21,1 \%(\mathrm{P}=0,01)$ and $3,2 \%$ vs. $12,2 \%(\mathrm{P}=$ 0.03 ), respectively. They concluded that the surgical correction of symptomatic CAs is better in preventing stroke compared with best medical therapy, as well as it completely eliminates the symptoms in patients with non-hemispheric symptoms. There are few other reports suggesting that the clinical course of carotid kinking can be benign. (34)

Different surgical techniques described for the management of carotid kinking: $(3,38)$

1) Arterial transposition, criticized for not removing arterial elongation.

2) Lysis of adhesions.

3) Vascular procedures such as segmental resection and end to end anastomosis.

4) Endarterectomy technique with eversion, which allows correction of severe elongation and kinking of the ICA.

The surgical technique of resection of tortuous segment, with dilatation and reimplantation has become the method of choice in treating carotid kinking and coiling. In the same procedure eversion carotide endarterectomy can be done. Correction of kinking and coiling is performed with peroperative mortality rate below $1 \%$ and low postoperative 
DOI: 10.2478/romneu-2014-0005

morbidity. $(5,13)$ It is noteworthy that all internal carotid reconstructive procedure is subject to technical difficulties and complications associated with surgery.

Surgical correction of CAs is indicated for patients with TIA (focal, hemispheric ischemic simptoms); patients in whom angiography demonstrated hemodinamically significant kinking and/or coiling; if CT and MRI examination excludes other significant ischemic brain injury; and in symptomatic and asymptomatic patients with one-sided CAs and occlusion of contralateral carotid artery; bilateral kinking and/or coiling, with the correction of one side first, if the symptoms do not disappear, then the other side as well, and patients with simultaneous lesions of vertebral artery. (13) There are reports showing that kink of ICA is a potentially hazardous condition and surgical treatment with revascularization offers good results. $(11,34)$ Some studies concluded that in patients with cerebrovascular insufficiency associated with stenotic kinking, ruling out any other cause of symptomatology, the kink correction improves symptoms and protects against recurrent ipsilateral cerebral ischemia. $(11,34)$

However, bilateral high kinking with distal dissection of ICA is indicated for surgical repair but only in cases with confirmed cerebral symptoms. This type of intervention is associated with frequent peripheral nerve lesions and high mortality rate. (13) Recurrences of kinking and coiling are rare and can appear in patients with uncontrolled hypertension. (20,37)

The ICA anomalies may be dangerous and represent a risk factor for massive bleeding. (3,43) Suture ligatures can penetrate and occlude torn vessels, scalpels or biting instruments can lacerate vessels, and indirectly conducted electric cauterization can burn the soft of bony tissues. (44)

\section{Angioplasty in carotid disease}

At present there are no studies addressing the kinking treatment by angioplasty with stent, the available information comes from studies performed on carotid angioplasty in atherosclerotic stenotic carotid disease. In recent years, carotid angioplasty with stenting has been an alternative, particularly in patients at high risk for carotid endarterectomy complications. (39)

The two aspects that drove the development of carotid angioplasty with stenting were seeking a better therapeutic option in high-risk patients and the tendency to perform minimally invasive surgery. Some authors suggest that this procedure is safer, less traumatic and more cost-effective than carotid endarterectomy.

Several clinical trials have compared stent angioplasty with carotid endarterectomy with similar results in terms of morbidity and mortalidad. $(40,41)$

Endovascular procedures have the inherent risk of damage to the intima and the subsequent risk of thrombosis; furthermore, all stents are thrombogenic, therefore, patients undergoing these procedures must receive antiplatelet therapy. Clopidogrel in combination with acetylsalicylic acid is currently the standard treatment. (42)

\section{Conclusions}

Abnormalities in the geometry and paths of the ICA are commonly identified in ultrasonography and angiography. 
58 Zenteno et al Implications of internal carotid artery tortuosity, kinking and coiling

Classification of CA in tortuosity, kinking and coiling was introduced in 1965 by Weibel and Fields. This classification offers tortuosity as an elongation in the form of "S" or "C"; coiling as the elongation or the redundancy of the artery, resulting in a deformation that resembles an $\mathrm{S}$ or a circular configuration.

The surgical correction of symptomatic CAs is better in preventing stroke compared with best medical therapy, as well as it completely eliminates the symptoms in patients with nonhemispheric symptoms. Currently is accepted that transient neurological symptoms produced by rotation of the head is an indication for the treatment of ICA kink.

The ICA anomalies may be dangerous and represent a risk factor for massive bleeding. Suture ligatures can penetrate and occlude torn vessels, scalpels or biting instruments can lacerate vessels, and indirectly conducted electric cauterization can burn the soft of bony tissues.

\section{Contributors}

A.L, H.A.M y and L.R.M contributed equally to the literature search and review and to the writing of this manuscript.

\section{Conflicts of interest}

MC, FV, AL, HA and LRM declares that they have no conflicts of interest.

\section{Corresponding author:}

Luis Rafael Moscote-Salazar, MD
Universidad de Cartagena, Cartagena de Indias, Colombia, Southamerica e-mail: mineurocirujano@aol.com

\section{References}

1. Akpek S, Arat A, Morsi H, Klucznick RP, Strother CM, Mawad ME. Self-expandable stent-assisted coiling of wide-necked intracranial aneurysms: a single-center experience. AJNR Am J Neuroradiol 2005; 26: 1223-31. 2. Bates MC, Kyer PD, Kavasmaneck C, AbuRahma A, Crotty B. Stent-supported angioplasty correction of symptomatic critical carotid angulation. W V Med J 2003; 99: 22-4.

3. Weibel J, Fields WS. Tortuosity, coiling, and kinking of the internal carotid artery. II. Relationship of morphological variation to cerebrovascular insufficiency. Neurology 1965; 15: 462-8.

4. Perdue GD, Barreca JP, Smith RB, King OW. The significance of elongation and angulation of the carotid artery: a negative view. Surgery 1975; 77: 45-52.

5. Ballotta E, Abbruzzese E, Thiene G, et al. The elongation of the internal carotid artery: early and longterm results of patients having surgery compared with unoperated controls. Ann Vasc Surg 1997; 11: 120-8.

6. Blanc R, Deschamps F, Orozco-Vasquez J, Thomas P, Gaston A. A 6F guide sheath for endovascular treatment of intracranial aneurysms. Neuroradiology 2007; 49: 563-6.

7. Byrne J. Interventional Neuroradiology: Theory and Practice, 1st ed. New York, Oxford University Press, 2002.

8. Metz H, Murray-Leslie RM, Bannister RG, Bull JW, Marshall J. Kinking of the internal carotid artery. Lancet 1961; 1: 424-6.

9. Koskas F, Bahnini A, Walden R, Kieffer E. Stenotic coiling and kinking of the internal carotid artery. Ann Vasc Surg 1993; 7: 530-40.

10. Togay-Işikay C, Kim J, Betterman K, et al. Carotid artery tortuosity, kinking, coiling: stroke risk factor, marker, or curiosity? Acta Neurol Belg 2005; 105: 6872.

11. Connors JI, Wojak J, editors. Interventional neuroradiology: strategies and practical techniques. Philadelphia, WB Saunders, 1999.

12. Vannix RS, Joergenson EJ, Carter R. Kinking of the internal carotid artery. Clinical significance and surgical management. Am J Surg 1977; 134: 82-9.

13. Radak D, Babić S, Tanasković S, et al. Are the carotid kinking and coiling underestimated entities? Da 
DOI: 10.2478/romneu-2014-0005

li su morfološke abnormalnosti karotidne arterije (kinking i coiling) 2012; 69: 616-9.

14. Fiorella D, Albuquerque FC, Deshmukh VR, McDougall CG. Usefulness of the Neuroform stent for the treatment of cerebral aneurysms: results at initial (36-mo) follow-up. Neurosurgery 2005; 56: 1191-201; discussion 1201-2.

15. Fisher RG. Strokes in children. Their relationship to intrinsic pathology of the carotid artery. Am Surg 1982; 48: 344-50.

16. Beigelman R, Izaguirre AM, Robles M, Grana DR, Ambrosio G, Milei J. Are kinking and coiling of carotid artery congenital or acquired? Angiology 2010; 61: 10712.

17. Benes V, Mohapl M. Alternative surgery for the kinked internal carotid artery. Acta Neurochirurgica 2001; 143: 1267-71.

18. Ozgur Z, Celik S, Govsa F, Aktug H, Ozgur T. A study of the course of the internal carotid artery in the parapharyngeal space and its clinical importance. European Archives Of Oto-Rhino-Laryngology: Official Journal Of The European Federation Of Oto-RhinoLaryngological Societies (EUFOS): Affiliated With The German Society For Oto-Rhino-Laryngology - Head And Neck Surgery 2007; 264: 1483-9.

19. Ovchinnikov NA, Rao RT, Rao SR. Unilateral congenital elongation of the cervical part of the internal carotid artery with kinking and looping: two case reports and review of the literature. Head \& Face Medicine. 2007; 3: 14-29.

20. Del Corso L, Moruzzo D, Conte B, et al. Tortuosity, kinking, and coiling of the carotid artery: expression of atherosclerosis or aging? Angiology 1998; 49: 361-71.

21Pancera P, Ribul M, Presciuttini B, Lechi A. Prevalence of carotid artery kinking in 590 consecutive subjects evaluated by Echocolordoppler. Is there a correlation with arterial hypertension? Journal of Internal Medicine 2000; 248: 7-12.

22. Pancera P, Ribul M, De Marchi S, Arosio E, Lechi A. Prevalence of morphological alterations in cervical vessels: a colour duplex ultrasonographic study in a series of 3300 subjects. Int Angiol 1998; 17: 22-7.

23. Taylor WR. Mechanical deformation of the arterial wall in hypertension: a mechanism for vascular pathology. Am J Med Sci 1998; 316: 156-61.

24. Weizsäcker HW, Lambert H, Pascale K. Analysis of the passive mechanical properties of rat carotid arteries. J Biomech 1983; 16: 703-15.

25. Hayashi K, Naiki T. Adaptation and remodeling of vascular wall; biomechanical response to hypertension. J
Mech Behav Biomed Mater 2009; 2: 3-19.

26. Stoitsis J, Golemati S, Bastouni E, Nikita KS. A mathematical model of the mechanical deformation of the carotid artery wall and its application to clinical data. Conf Proc IEEE Eng Med Biol Soc 2007; 2007: 2163-6.

27. Rosenthal D, Stanton PE, Lamis PA, McClusky D. Surgical correction of the kinked carotid artery. Am J Surg 1981; 141: 295-6.

28. Van Damme H, Gillain D, Désiron Q, Detry O, Albert A, Limet R. Kinking of the internal carotid artery: clinical significance and surgical management. Acta Chir Belg 1996; 96: 15-22.

29. Higashida RT, Meyers PM, Phatouros CC, Connors JJ, Barr JD, Sacks D. Reporting standards for carotid artery angioplasty and stent placement. Stroke 2004; 35: e112-34.

30. Huemer M, Emminger W, Trattnig S, Freilinger M, Wandl-Vergesslich K. Kinking and stenosis of the carotid artery associated with homolateral ischaemic brain infarction in a patient treated with cyclosporin A. European Journal of Pediatrics 1998; 157: 599.

31. Beigelman R, Izaguirre A, Robles M, Grana D, Ambrosio G, Milei J. Kinking of carotid arteries is not a mechanism of cerebral ischemia: a functional evaluation by Doppler echography. Int Angiol 2011; 30: 342-8.

32. La Barbera G, La Marca G, Martino A, et al. Kinking, coiling, and tortuosity of extracranial internal carotid artery: is it the effect of a metaplasia? Surgical And Radiologic Anatomy: SRA 2006; 28: 573-80.

33. Howington JU, Hanel RA, Harrigan MR, Levy EI, Guterman LR, Hopkins LN. The Neuroform stent, the first microcatheter-delivered stent for use in the intracranial circulation. Neurosurgery 2004; 54: 2-5.

34. Hunt WE, Kosnik EJ. Timing and perioperative care in intracranial aneurysm surgery. Clin Neurosurg 1974; 21: 79-89.

35. Nishino K, Ito Y, Hasegawa H, Kikuchi B, Fujii Y, Tanaka R. Modified buddy wire technique for coil embolization of posterior circulation aneurysms. Neuroradiology 2007; 49: 49-55.

36. Ballotta E, Thiene G, Baracchini C, et al. Surgical vs medical treatment for isolated internal carotid artery elongation with coiling or kinking in symptomatic patients: a prospective randomized clinical study. J Vasc Surg 2005; 42: 838-46; discussion 846.

37. Bowen JC, Garcia M, Garrard CL, Mankin CJ, Fluke MM. Anomalous branch of the internal carotid artery maintains patency distal to a complete occlusion diagnosed by duplex scan. J Vasc Surg 1997; 26: 164-7. 
38. Kis B, Weber W, Berlit P, Kühne D. Elective treatment of saccular and broad-necked intracranial aneurysms using a closed-cell nitinol stent (Leo). Neurosurgery 2006; 58: 443-50; discussion 443-50.

39. White JB, Kallmes DF. Utility of the "buddy" wire in intracranial procedures. Neuroradiology 2008; 50: 185-7.

40. Yuzawa I, Kurata A, Suzuki S, et al. Efficacy of a direct puncture approach for anterior circulation aneurysms using a newly developed guiding catheter especially for geriatric patients. Surg Neurol 2007; 67: 30-4; discussion 34.

41. Zenteno M, Modenesi Freitas JM, Aburto-Murrieta Y, Koppe G, Machado E, Lee A. Balloon-expandable stenting with and without coiling for wide-neck and complex aneurysms. Surg Neurol 2006; 66: 603-10; discussion 610.

42. Zenteno MA, Santos-Franco JA, Freitas-Modenesi $\mathrm{JM}$, et al. Use of the sole stenting technique for the management of aneurysms in the posterior circulation in a prospective series of 20 patients. J Neurosurg 2008; 108: 1104-18.

43. Galletti B, Bucolo S, Abbate G, et al. Internal carotid artery transposition as risk factor in pharyngeal surgery. Laryngoscope 2002; 112: 1845-8.

44. Sho E, Nanjo H, Sho M, et al. Arterial enlargement, tortuosity, and intimal thickening in response to sequential exposure to high and low wall shear stress. J Vasc Surg 2004; 39: 601-12. 